\title{
Symbiosis Principle: The Basic Principles of the Community of Common Destiny
}

\author{
Qianqian Yang \\ Renmin University of China School of Philosophy \\ Renwen Bldg., 59 Zhongguancun Rd. \\ Beijing, China \\ Yunnan University of finance and economics law school \\ Boyuan Bldg., 237 Longquan Rd. \\ Kunming, China \\ yqqhelen@ruc.edu.cn
}

\begin{abstract}
From traditional human geography, consanguinity, out of the political community, to the transformation of modern community is in essence the individual mutual ties changed, namely by dominated by emotion, clan, beliefs, social relations to benefit or value pursuit of social relations, the nature harmonious to fit the homogeneity and interdependence symbiotic heterogeneity. The community of common destiny is the highest and highest stage of community development, and it is also the ideal realization and value pursuit of the highest good on the basis of realizing the common good. Human destiny community with heterogeneity, transcendence, voluntary characteristics, symbiosis principle is the basic principle, the community to produce at the same time and to maintain the necessary premise and basis of community action. From the principle of symbiosis, the basic principle of the community of common destiny is the logical starting point, and it tries to understand the construction path of the community of human destiny from the three aspects of subject, behavior and system.
\end{abstract}

Key words - the symbiosis principle; ethical spirit; moral meaning; community of common destiny

\section{INTRODUCTION}

Human society determines that everyone lives in one or more communities, which is the basic way of human society. As Karl Heinrich Marx said, "the essence of man is the real community of man" [1]. The process of community change is the process of human evolution. Community is the organic organization of people's social interaction and coordinated action. So, we need to ask, what is the purpose of the community? Is there an internal purpose for the community to achieve the realization of the common good? Is the good that people finally achieve is achieved overnight? Answer this a series of problems, we need to trace community of human development, human destiny community for each individual survival, for the country is safe, for the world is peaceful, as an activity of human civilization and perpetuate the premise of the importance of self-evident. In addition, this article also wants to explore the question: how does "symbiosis" play a role in the community as a principle? Specifically, based on the social relationship is a basic fact of anthropology, then how people from symbiotic joint cooperation relationship into a community, and how in international relations, especially in the coexistence of pluralistic value of international political work? And symbiosis principle if it is possible, or how to get a kind of moral connotation, whether the principle of life as a moral principle can briefly Outlines its main contents and requirements, and so on.

\section{THE ACTUAL ANALYSIS}

\section{A. From Ethnic Groups to the Community of Human Destiny}

The so-called community refers to a social group with a common historical tradition, cultural background or common belief, value goal, normative system, and stable relationship. The community has existed since ancient times, but the concept of the concept of the community has not appeared until modern times. Now from the point of literature at home and abroad, it is generally believed that the word "Community" first appeared in the German sociologist Ferdinand, vines, nice (Tönnies, Ferdinand) 1887 book "Community and Society" (Gemeinschaft und Gesellschaft, English translation for the Community and Society) in the proposed. Vines nice with "community" (Gemeinschaft) to represent based on natural emotion and exclusive social ties or way of life, the universe produce conditions often more to do with geography, kinship, clan, religious, beliefs, depends on the natural order of the society, in the realistic society often in the form of family, clan, village, village of natural attributes such as social structure [2] In this brutal to wild until before the transition to the modern community, a most obvious feature is that morality and traditional rules become community cohesion, mainly in the overall value of the value of the entity attached to the community, all the significance of its existence is to maximize the interests of the community, as a result, individuals tend to be submerged in the community, but it was also in this community, each individual can gain their sense of belonging and spirit. In traditional community, people will often form the convergence of emotional experience and common faith, collective consciousness and belief not only strong and intense, solidarity of the relationship between individual and community makes every one of us are highly dependent on 
community, also makes it hard for the individual and the collective consciousness. Family the form a complete community carry the economy, the function of the religion, politics and science and other fields, has unified the nature of the inseparable, family is everyone and self-restraint selfsacrifice spirit of classroom learning, is the supreme moral holy land, to as a link to a blood relationship, it's easy to put personal together, it can naturally put different consciousness into harmony with each other. The similarity of constitution, the unity of interest, the need to deal with the enemy of the enemy, or the union alone, can combine to form a different form.

But with the social production, trade development, each work constantly differentiation, professional is playing a more and more important status in our life, people fled out of the family to find new markets, exchange and trade activities, compete with counterparts across the region to promote the circulation of commodities at the same time, the influx of a large number of immigrants also makes the urbanization process is accelerated, human relations from the original family, kinship, evolved into the acquaintance relationship and contractual relationship established between strangers, visible, prototype has formed the community of modernity, it with concentrated, open, flow characteristics of driving the small, close, close to the characteristics of the former modern community to decay. Individual rational man after has made its own control, no longer belongs or bound to the family or community, but in connection with others and won the status in social activities, so as to have the intrinsic value of independence and individual consciousness.

Type of individual atoms, a great change have taken place in human relations, from the original more close to the distance, as described in Marx and Engels in the communist manifesto: "its ruthless cuts off the bind natural leaders among people of all sorts of feudal yoke, it make in addition to the naked relationship of interests between person and person, in addition to callous 'cash transactions', no any other contact. It reverses the sacred heart of religious piety, chivalry, and petty citizens, drowning in the icy waters of egoism" [3]. Community members new behavior once established, the need to create a new structure to adapt to this kind of behavior, so people established a new group, namely the corporate bodies, it is the first in the form of a family to take on its stable function, at the same time set up a series of moral and law and play a role and effectiveness.

\section{B. Common Interests of Mankind: a Realistic Basics for a Community of Shared Future for Mankind}

According to fei xiaotong: "In sociology, we often separated two different nature of the society, a kind of no specific purpose, just because the growth of society, in order to complete a task and combining with the society. The former is a civil society, the latter a legal society" [4]." In the writings of Émile durkheim and Léon Duguit, the use of "social solidarity", also analyses the two different of society, if we will make our corresponding Chinese and western on the description of the social form, then is the unity of "mechanical solidarity", and legal society (the unity caused by division of labor) is the unity of "organic solidarity" [5]. To note here is that the "social solidarity" and "social joint" is referring to the same meaning, the word "joint" in Chinese is by Japanese shift, the earliest French "solidarité" translated into Japanese "joint" is fully fit, because Japanese "joint" means "to help each other, unity, cooperation," there is no Chinese in the "joint" we usually use the meaning of "social joint" more accord with the real intention of foreign origin, closer to the division of labor in Émile durkheim said the meaning of unity.

People in the community for the certainty and a sense of security, belonging and other spiritual comfort and satisfaction, and loss of community, means a loss of identity and the value of individual confirmed that people no longer feel certainty and sense of belonging. Facing the complicated and changeable modern society, the community increasingly become people to seek material benefits, get the intellectual support for the important carrier and method, people through the new community looking for the lost their homes, such as political community, the academic community, professional community, economic community, community of fate, and so on. As the sociologist Zygmunt Bauman puts it: "the community is a lost paradise, or a paradise that people still want to find" [6]. Based on the modern community pay more attention to common interests, identity, value realization and the sense of belonging, benefit maximization become the main target of the individual and collective action, the realization of common interests and interest community formation and existence of endogenous power. In particular, the human society by "mechanical solidarity" into the "organic solidarity" is in essence the individual mutual ties has changed, the dominated by emotion, clan, beliefs, social relations to benefit or value pursuit of social relations, by the natural harmony to fit the homogeneity and interdependence symbiotic heterogeneity. Therefore, we conclude that the stronger the heterogeneity of the social community, the weaker the social solidarity, and conversely, the weaker the heterogeneity of the community, the stronger the social solidarity.

\section{Symbiosis: the Ethical Spirit of a Community of Shared Future for Mankind}

1) The heterogeneity of the community of human destiny

If the general community is a collection of different individuals, the basic unit of the community of common destiny is different countries or different national communities. Historically, the process of globalization is an individual country in the process of from traditional state to modern state, and national individual process, namely, individual countries from bondage to take off the embedded in the structure or attachment system and realization of the process. Both the British and French revolution, and the independence, no matter many national colonial system from the west after world warII, or Warsaw pact is dissolved and the collapse of the Soviet union in the 1990s, countries are showing obvious individualized tendency, the independence of the individual countries continue to strengthen, the individuality has been achieved. Although in this process, the new national community, such as a postwar international union, NATO and Warsaw pact after world war ii, the United Nations and OPEC, the African union, the Arab league, the association of southeast Asian nations etc., and some new post-cold war 
international cooperation organization or cooperative mechanism appeared, but the individualized trend has not changed, "global interests, values and ethics at present is still in the growth stage, the country is still in the development of human beings rely on primary political, economic, and cultural space" [7]. In a sense, globalization has not changed but increased the diversity and diversity of countries. Therefore, the heterogeneity of the members of the international community is still the most basic premise of the community of human destiny.

2) The transcendence of the community of common destiny on the goal

Human destiny community has transcendence, is not only the superiority of its own purpose, which aims to promote the development and progress of human civilization, more major is to go beyond the human destiny community the fetters of reality. One is human destiny community beyond ideological conflict and system model of prejudice, abandon the zero-sum thinking, out of the dilemma of the cold war, the call to cooperate, emphasis on understanding and trust, commitment to the common governance, the pursuit of win-win cooperation. Second, human destiny community claims beyond the western civilization "universalism", to get rid of the superiority of western culture on the basis of "interpretation" and "history of the end" barriers, advocate of learning between different cultures and using for reference. Three community of human destiny is beyond the shackles of absolute nationalism and barriers, beyond the self-interest of a nation and of the gain and loss, the realization of a country's interests to the transformation of the common interests, on the basis of grasping human interests and value, the maximum common divisor of cooperation between different subjects and different interests is sought.

3) The voluntary nature of the community structure of human destiny

Human destiny community basic unit is a country, although the human destiny community is in essence the international community member countries of collectivism, it is not mandatory, however, is exclusive, its intrinsic logic is the equality between countries subject, its implementation is the premise of coexistence of voluntary or a certain degree of identity. Human destiny community structure of the relationship between different countries is a community of support and protection responsibilities and obligations of the relationship between each other, share responsibilities, working together, any one party should not unilaterally violate the obligations of members of the community in the pursuit of its interests at the same time give attention to both reasonable concerns of other countries. Therefore, the community of human destiny is a flexible and dynamic network of organizations with apparent looseness in structure.

Fate community beyond the general sense of community types and their value, and the integration of various kinds of community spirit and character convergence and dialectical unification, ethical core embodied in the interests of symbiosis, emotional resonance, value consensus, development and winwin and Shared responsibility, building up is a kind of selfinterest and altruistic benefits with national and community interest organic combination of symbiotic win-win development mode of ethics, has the utilitarian and moral, purpose and means, the organic combination of inner and outer ethical characteristics, highlight in the same boat, share the joys and sorrows, unite as one of ethical spirit and value significance.

\section{Win-win Cooperation: the Moral Principle of Handling International Relations}

The biological symbiosis of naturalistic philosophy is derived from the "symbiosis" of a biological term. Oxford Advanced Learner's English-Chinese Dictionary defines it as "relationship between two species, organisms, etc. that live close together and depend on each other in various ways."[8]It is a symbiotic relationship. Xiandai Hanyu Cidian defines "symbiosis" as: two different creatures living together, mutually beneficial to each other, and this way of life is called symbiosis [9]. The etymology of Symbiosis can be traced back to the ancient Greek word for " $\sigma \nu \mu \beta i ́ \omega \sigma \iota \varsigma ", ~ " \sigma \nu \mu "$, which

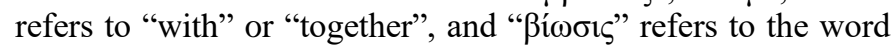
"life" or "living", which evolved into an English word in the middle ages. Symbiosis as "the ability of all groups are closely combined, but many branch of life science and the theory of network, and is a kind of life philosophy, the nature and the humanities, etc." The biological symbiosis law maintains the life order of nature, and safeguards biological evolution and species innovation. This natural law not only obtains the demonstration of natural science, but also evolves from a kind of natural biological symbiosis philosophy into a kind of generalized social symbiosis philosophy. Now, the symbiosis theory has become a new methodology in many humanities and social sciences, and it has become a modern social thinking mode universally applicable.

As Karl Heinrich Marx said, "what is society,whatever its form? It's the product of interaction" [10]. That is to say, in the symbiotic relationship between "people interaction", society is generated, and social symbiosis is in turn to regulate "people interaction", thus the social and historical movement is born. Whether gemeinschaft is the unity of "mechanical solidarity" symbiosis, "organic solidarity" symbiosis or legal society there are interaction, interdependence, mutual influence, this means that the society has the features of pluralism and coexistence. Along with the formation of the world capital markets, community have already crossed the boundary of the original time and space, in any subject, any behavior of pluralism and coexistence society, all have to face how to balance the capital and the social logic of pluralism and coexistence. Capital as the value of generating surplus value, its self-realization relies on a logical relation, which is called capital logic. It is the premise condition of money into circulation field, currency holders found in the market of symbiotic relationship is a kind of special commodity of special value labor force, thus producing surplus value. Workers live through mental physical labor, not only to create value, but also can create value is much bigger than its own value, labor and money two combined to produce the value of surplus value, can also be converted into capital. In the process of seeking self-actualization between the labor owner and the holder of money, the mutual dependence of each other for mutual benefit forms a symbiotic logic. Thus, capital 
logic is not only a social logic, and from plural homobjum logic belongs to the society, its vitality lies in whether can curb capital trend of barbarization, society as a whole reasonably pluralistic symbiosis. Capital logic every forward step will involve social balance and rationality of plural homobjum logic problems, all have to face a series of problems, such as: Labour owner's relationship with money holders, abstract labor and the labor relationship, the relationship between commodity value and use value, etc.

With the refinement of social division of labor, the interdependence of commodity producers is becoming more and more closely, and it is increasingly difficult and complicated to realize the contradiction between abstract labor and concrete labor. This process inevitably involves the question of how to balance the production capital and financial capital, aggregate supply and social demand, economic structure and economic relationship. And this series of problems extends to the core values of medical treatment, education, housing, social assistance, vulnerable groups and members of society. It is not difficult to see how to solve the problems of the welfare of people's livelihood and unbalanced economic development. It can neither rely on capital power nor rely on individual capital, but need to comprehensively improve the governance capacity of modern society. Countless historical facts tell us that the capital logic is inseparable from the community of interests, the community of responsibility and the community of common destiny. Capital cannot cover everything; Capital cannot survive on its own. "Capital is labor without vitality" means profit is the instinct, has its rationality, but a lack of its own reason, though, is the person's subjective value conscious, rational, and cannot be indulged in "capital thinking".

Whether it is the social logic or the pluralistic symbiosis logic, its logical connotation is the value consideration of the human existence way. People on the basis of meet the needs of their own survival, and development goal, and to respect the development goals for logic, respect for the logic of public reason, as far as possible from their own instincts, blindness and randomness. Because of capital caused by irrational trend of barbarization must rely on people to the public reason to restrict capital logic implementation, this is the Chinese traditional philosophy of "Yin and Yang are in harmony", and "there is always one thing to conquer another" the idea of dialectics. The ability of human to understand capital, use capital and harness capital is obtained under the logic of social pluralism. In the development of commodity economy hundreds of years, human society has experienced crisis, war, poverty and famine, and again in this process, however, the capital of understanding and the ability to continuously improve, restrict capital barbarization trend of public rationality is increasingly mature, including the rational requirements for competition. In any field, the interests of the community of human destiny is complex, multi-layered, the competition between diverse interests not only injected vigor and power to the society, also forced all the behavior subjects to self-reliance. However, the competition needs to abide by the bottom line principle, the orderly principle, needs the competition to have the degree. The rights and interests of the relevant parties in a pluralistic and symbiotic society are symbiotic, and their respective powers and interests are premised on the recognition, recognition and acceptance of the other, without excluding the other. Although their respective interests are large and small, they have mutual benefits based on mutual benefit and mutual benefit, which leads to the formation of a symbiotic relationship.

\section{CONCLUSION AND DISCUSSION}

\section{A. What is the Symbiotic International Order?}

Symbiotic type international order refers to the actors in the international society in certain internal and external environment, the role of a mechanism, influence each other, promote each other, live together and common development, the resulting order type is the symbiosis international order. The national assembly under the symbiotic international order is called the symbiotic system.

\section{B. The Direction of the Optimization of Symbiotic International Order}

To construct and optimize the symbiosis international order, the key point is to constantly improve the symbiosis of the international community in political, economic and cultural fields. Promote symbiotic type international order development in the direction of its evolution, we must follow some basic principles and concrete manifestation is: the countries to give up endless pursuit of power and interests, with the development of a country does not damage the interests of other countries, and can let others share the benefits of a country's development, achieve mutual benefit and win-win results in mutual cooperation and to increase the degree of symbiosis.

\section{The Basic Principle of the Symbiosis International Order Should be Followed:}

1) Do not violate the common nature bottom line.

In the process of symbiosis of any country or subject, there is an adjacent line or critical point that is not counted and must be tolerated by each other. Fate community of symbiotic line as the core of a country's national interest, when touch the core national interests, any country can fight, and also to maintain the core national interests at any cost. But different countries or a country in different periods of development and the content of its core national interests is also different, this requires our attention to the analysis of different period of the change of the core national interests, and do not touch each other in the midst of exchanges between the core national interests, namely common adhere to the principle of the symbiotic bottom line.

\section{2) Balanced distribution of interests.}

The unequal distribution of long-term benefits can easily lead to contradictions or conflicts between countries. Although through symbiotic international order will lead to the increase of the symbiosis net energy, but if the uneven distribution of energy increases, or the more extreme cases, energy increase is assigned to a part of the country, not enjoy the symbiosis benefits countries will hold the negative attitude of cooperation or sabotage symbiotic type international order. This equilibrium is not to say that any economic symbiosis energy, political or cultural symbiosis symbiotic energy is completely 
evenly distributed to all members, but refers to the total energy distribution between the member states to be roughly balanced. In a symbiotic system, for example, some countries demand for symbiotic may be enjoyment from other countries for its consumer market to expand, in some countries is in the demand for symbiosis symbiotic bring its peaceful environment, and the other countries may also be to enjoy the symbiotic economic competitiveness and so on.

3) Mutual tolerance and respect for each other's culture.

The cultures of the nations of the international community cannot be exactly the same, and each country has its own unique cultural history and values. Although some countries may have similar cultural foundations, it is easier to achieve cultural consensus in communication, but it is not enough to show that the two cultures are identical. Cultural diversity is universal in the international community. In mutual exchanges, the countries should have cultural consciousness, while insist on local cultural subjectivity, can fully understand the culture of "the other", respect for cultural differences, allowing diversity culture, realize the cultural coexistence and coprosperity.

\section{4) Rights and obligations are equal.}

Rights and obligations are concomitant, and there is no duty without rights, and no rights without obligation. The acquisition of power is bound to have the obligation to pay, at the same time, the obligation to pay also corresponding to the acquisition of rights. This principle is embodied in the domestic society, is a country's citizens should fulfill corresponding obligations when in power, and in the performance of the obligation can be to meet its social in material life and spiritual life needs. In the symbiotic system, countries can enjoy the benefits of symbiosis in political, economic, cultural and other fields, and also bear the responsibility to maintain symbiosis. Can the international community is not a true beyond government agencies to implement supervision and punishment, therefore, to maintain international order needs not only the instincts symbiotic type, more countries need to power and the obligation to criteria, a joint statement, a form of cooperation agreements and cooperation mechanism to clarity and certainty. This is like the need for various laws and regulations in the domestic social field to maintain the operation of the society. The symbiosis international order wants to exist for a long time, and it also needs institutions and rules to guarantee it.

In contemporary international society, symbiotic first should be the development of not stagnant, should be advanced and not backward, should be rich and strong, not weak, it is not only benefit the Chinese people's growing material and cultural needs of their own and is beneficial to the construction of a harmonious society, but also beneficial contribution for the international community, promote common development. The international community is symbiotic, and all relations between all countries are symbiotic through various symbiotic links. In the links of various symbiotic relations, there must be similar tolerable and mutually inclusive adjacent lines or critical points between relevant parties, forming a common bottom line. If problems occur on the common bottom line between countries, causing all parties concerned to lose their ability to bear them, then the symbiotic relationship will not only lose the basis of harmony, but also lead to crisis. There are various symbiotic bottom lines in the international community. When these bottom lines are expressed in the form of some international rules and institutions, they constitute the international political and economic order. International political and economic order is essentially solve countries on all kinds of symbiotic relationship between the problem of how to construct the symbiotic bottom line, is to provide a common how to build a harmonious world. In the white paper on "China's peaceful development" as China's core national interests of the state sovereignty, national security and territorial integrity, national unity, the constitution of the country's political system and social stability, the basic guarantee of sustainable economic and social development, there is no one aspect is the special requirements of China, is any country can concentrate and national power to maintain and defend. Countries are similar to each other on the bottom line of their own survival and development, thus forming the common bottom line of international relations. Harmony of the international community is not to say that no contradiction, friction, and even conflict, but in the bottom line on the symbiotic can tolerate each other, mutual tolerance, and to the international rules, the system of international political and economic order as guarantee, solve contradictions have the common basis and the rules of the game.

\section{ACKNOWLEDGMENT}

This work was supported by the Science Foundation and Major Project of Educational Committee of Yunnan Province (No. 2016ZZX139); The National Science Education "in 13th Five-Year" 2016 year project planning of National Social Science Fund (No.CGA160207).

\section{REFERENCES}

[1] Marx Karl, "Economic and philosophic manuscripts of 1844", Mineola, New York : Dover Publication, Inc., 2007,pp23

[2] Tönnies, Ferdinand, "Gemeinschaft und Gesellschaft, Leipzig: Fues's Verlag", An English translation of the 8th edition 1935 by Charles P. Loomis appeared in 1940 as Fundamental Concepts of Sociology (Gemeinschaft und Gesellschaft), New York: American Book Co. pp.138-156.

[3] Marx, Karl, "The Communist manifesto" New York, Monthly Review Press, 1964, pp. 45-48.

[4] Fei xiaotong, "From the Soil" Shanghai: Guancha, 1948. (Translated as From the Soil: The Foundations of Chinese Society, U. of California Press, 1992, pp.32)

[5] Durkheim, Emil, "The Division of Labour in Society" Trans. W. D Halls, intro. Lewis A. Coser. New York: Free Press, 1997, pp. 39, 60, 108.

[6] Bauman Zygmunt, "Community. Seeking Safety in an Insecure World", Cambridge: Polity press, 2003, pp. 125.

[7] Wenger Etienne, "Communities of Practice: Learning, Meaning and Identity”, Cambridge University Press, Cambridge, 1998. pp. 23

[8] Oxford Dictionaries. China the Commercial Press edition, 2014, pp. 133

[9] Chinese Academy of Social Sciences Research Institutes of Language Department of Dictionary, Xiandai Hanyu Cidian, Commercial Press, 2016, pp. 127

[10] Marx Karl, "Wage labour and capital", Reprint. Originally published: Chicago: Charles H. Kerr Company, 1891, pp.23 